\title{
Akran Koçluğu ve Portfolyo Kullanımı: Etkili Öğretim Denetiminde İki Yöntem ${ }^{1}$
}

\author{
DOI: 10.26466/opus.676497 \\ $*$ \\ $\underline{\text { Yasin Avan* - Sevilay Şahin ** }}$ \\ * Maarif Müfettişi / Milli Eğitim Bakanlığı / Sivas \\ E-Posta: y.avan@hotmail.com \\ ORCID: 0000-0003-2622-2982 \\ ** Doç Dr, Gaziantep Üniversitesi /Eğitim Fakültesi, Gaziantep /Türkiye \\ E-Posta: $\underline{\text { ssahin@gantep.edu.tr }}$ \\ ORCID: 0000-0002-7140-821X
}

\section{Öz}

Araştırmanın amacl, öğretim denetiminde akran koçluğu ve portfolyo yöntemleri kullanılmasının etkililiğinin öğretmen görüşleri doğrultusunda incelenmesidir. Bu çalışmada nitel araştırma yöntemi kullanılmıştır. Araştırmanın amacına uygun olacağı düşünülerek, nitel araştırma yöntemlerinden durum çalışması seçilmiştir. Araştırma verileri, odak grup görüşmesi yapılarak toplanmıştır. Araştırma 2017-2018 eğitim öğretim yılında yapılmıştır. Çalışma grubunu, Sivas ili merkezinde görev yapan 25 okul müdürü ve 25 öğretmen oluşturmaktadır. Veri analizinde içerik analizi yöntemi kullanılmıştır. Araştırma sonuçlarına göre, katılımcilar öğretim denetiminde, akran koçluğu ve portfolyo kullanılmasının etkili yöntemler olduğunu düşünmektedirler. Ayrıca yöntemlerin, öğretmenin sinıf içi uygulamalarda karşılaştığı sorunların çözümüne katkı sunan, mesleki gelişim sağlayan denetim araçları olduğunu belirtmişlerdir. Ortaya çıkan sonuçlar bağlamında araştırma için şu öneriler getirilebilir: Öğretmenler, öğretim denetiminde akran koçluğu ve porfolyo yöntemlerini kullanarak sinıf içi uygulamalardaki karşılaşttğg sorunların çözümüne katkı sunabilir ve bu yöntemleri mesleki gelişim veya denetim aracı olarak da kullanabilirler. Öğretim denetiminde akran koçluğu ve portfolyo gibi daha demokratik yaklaşım biçimlerinin kullanılması konusunda pilot çalışmalar yapılarak araştırmacı ve uygulamacilara ışı tutulabilir.

Anahtar Kelimeler: akran koçluğu, portfolyo, öğretim denetimi, öğretmen gelişimi

\footnotetext{
${ }^{1}$ Makale Gaziantep Üniversitesi'nde yapılmakta olan "Öğretimsel denetim uygulamaları yoluyla öğretmenin sınıf içerisinde geliştirilmesine yönelik bir eylem araştırması" konulu doktora tez çalışması kapsamından üretilmiştir.
} 


\title{
Peer Coaching and Portfolio Usage: Two Methods in Effective Instructional Supervision
}

\begin{abstract}
The aim of the research is to examine the effectiveness of peer coaching and portfolio methods in instructional supervision with through the opinions of teachers. In this study qualitative research method was used. Considering that the research will be suitable for its purpose, case study was chosen from qualitative research methods. The data of the research was collected through a focus group interview. The research was conducted in 2017-2018 academic year. The study group consists of 25 school principals and 25 teachers working in Sivas city center. Descriptive analysis method was used in content analysis. As a result of the research, the participants think that the use of peer coaching and porfolio are effective methods in instructional supervision. They also state that the methods are supervision tools that contribute to the solution of problems faced by the teacher in the classroom practices and provide professional development. In the context of the resulting results the following suggestions can be made: Teachers, peer coaching and portfolio in teaching supervision methods to contribute to the solution of the problems faced in classroom applications and use these methods as a tool for professional development or supervision. More democratic approaches such as peer coaching and portfolio in teaching supervision can shed light on researchers and practitioners by conducting pilot studies.
\end{abstract}

Keywords: peer coaching, portfolio, instructional supervision, development of teacher 


\section{Giriş}

Eğitim kurumlarında denetim çıtıların değerlendirilmesi, kurumun gelişiminin sağlanması ve geleceğinin görülmesi açısından önemlidir. Eğitim denetimi, kamu faydası adına faaliyetleri kontrol etme süreci (Bursalığlu, 2000) olarak görülmüştür. Denetimle beraber okulların amaçlarından sapması engellenerek gerekli iyileştirmelerin yapılmasına firsat verilir (Lunenburg ve Ornstein, 2014). Bu süreçle beraber okulda ve sınıf içerisinde öğrenmeye katkı sağlayan ortamlar oluşturularak öğretmene yardımcı olunur (Henson, 2010). Öğretime ilişkin faaliyetlerin okul işleyişi ile eşgüdümlü olarak yürütülmesi (Wiles ve Bondi, 2000) sağlanır ve öğrenmeyi daha etkili kılmak adına okul işleyişi ve öğretim gerektiğinde yeniden biçimlendirilebilir (Aydın, 2011).

Günümüzde yeni yönetim anlayışlarının gelişmesi ve örgütsel öğrenmenin öne çıkması, denetim anlayışlarının değişimine neden olmuştur (Senge, 2006; Sullivan ve Glanz, 2009). Bu çerçevede; klinik denetim, öğretimsel denetim, farklılaşmış denetim, gelişimsel denetim, yansıtıcı denetim (özdenetim), mentörlük, koçluk (bilişsel koçluk, akran koçluğu), portfolyo, eylem araştırması gibi denetim anlayışları zamanla ortaya çıkmıştır. Katı kuralcı bürokratik anlayışın terkedilmesi, insancl anlayışa doğru yönelme, öğretmenin motive edilmesi, öğretmenin mesleki gelişimi, bireysel farklılıkların temel alınması, denetimde iletişim kanallarının açık tutulması, demokratik tutum geliştirilmesi ve öğrenci başarısına odaklanılması eğitim denetiminde ön plana çıkan durumlardır (Aydın, 2013; İlgan, 2012; Marzano, Frontier ve Livingston, 2011). Bu yöntemlerden olan akran koçluğu, Bandura (1986) tarafından geliştirilen sosyal öğrenme teorisine dayanmakta olup teori akran koçluğunun anahtar özellikleri olan gözlem ve modellemeyi içerip karşlıklı öğrenme esasına dayanır(Zepeda, 2016). Joyce ve Showers'ın (1982), hizmet içi eğitimle öğretmenlerin mesleki gelişiminin sağlanması için akran çalışmalarına ağırlık vermesi modelin ilk temelini teşkil etmiştir. Robbins (1991), akran koçluğunu karşılıklı güvene dayalı, yeni beceri kazanarak öz değerlendirme yaptıkları, paylaşımcı, öğretici, sorunları çözücü, meslektaşların birlikte yaptığı uygulamalar, Zepeda (2016), öğretmenlerin birbirini desteklediği, hem kendilerinin hem de öğrencilerin öğrenme süreci hakkında gerçekçi tartışma yaptığı, bir mesleki gelişim ve öğretim denetimi modeli; Browne (2006), akran koçluğunu paydaşlara geniş görüşlülük kazandı- 
ran motivasyonu olumlu yönde etkileyen bir çeşit değişim modeli olarak tanımlamıştır. Bu değişim süreci kişiyi, durumu, olayı ve davranışı değiştirmeye odaklı olup birtakım taktikleri kapsamaktadır. Kişilerde duygusal, teknik farkındalık odaklı bir ihtiyaç oluşturulması durumunda, yetersizlikleri ve sorun alanlarının aşılabileceği düşünülmektedir (Browne, 2006).

Akran koçluğu eşitlikçi, hiyerarşik olamayan eşit düzeyde ortaklı̆̆ı, değerlendirme olmadan mesleki gelişimi ve yardımlaşmayı amaç edinir (Aydın, 2013; Bowers, 1999; Knight, 2011; Sullivan ve Glanz, 2000). Buna benzer şekilde Anderson (2013), akran koçluğunu bir öğrenme stratejisi olarak tanımlamış, kuramsal bir çerçeveye oturtmuştur. Bu anlayışta koçlar, öncelikli olarak sorun alanlarını danışanla beraber tespit ederler. Koç yardım isteğine karşılık verirken, alana yönelik yaptı̆̆ çalışmalarla farkındalı̆̆ı arttırmaya öncelik verir (Anderson, 2013; Rhodes ve Beneicke, 2002). Böylece sorun alanı; çözüm sürecine giden, öğrenme fırsatı sağlayan bir forma büründürülmüş olur. Akran koçluğu, disiplinler arası stratejilerin uygulanmasını sağladığından inovasyonu tetikleyip güçlendirmektedir (Browne, 2006; Robbins, 1991; Xun ve Land, 2004). Ayrıca yeni öğrenilen becerilerin ve fikirlerin paylaşıldığı rahat bir ortam sunmaktadır (Joyce ve Showers, 1982; Robbins, 1991).

Akran koçluğu modeli üç aşamalı bir döngüyü takip etmektedir (Zepeda, 2016). Bu aşamalar gözlem öncesi görüşme, sınıf gözlemi ve gözlem sonrası görüşme şeklindedir. Gözlem öncesi görüşme; gözlenecek öğretim becerilerinin seçilmesi, ders planının ele alınması, öğretim becerileri hususunda nasıl bilgi toplanacağına karar verilmesi, gözlemci durumunda bulunan koç ile öğretmenin ortak hedefler belirlemesi, okulun, danışanın, öğrencilerin ihtiyaçları doğrultusunda hedef oluşturulması ve kullanılacak stratejilerin belirlenmesini içerir (Guskey, 2014). İşbirlikçi olan bu denetim sürecinde, öğretmen ve akran koçu hedefleri belirlemek için gayret gösterirler. Kullanılabilecek stratejiler birlikte değerlendirilmektedir. Sınıf gözlemi; koçun görüşmede belirlenen bu becerilere odaklanması öğretmen veya öğrencilerin söylediği ya da yaptı̆ı etkinliklerin nesnel olarak yapılması faaliyetlerini içerir (Rice, 2012). Bu aşamada daha önce hedeflenmiş ve tespit edilen öğretim davranışlarına yönelik oluşturulan gözlem formları, verilerin toplanmasına katkı sağlamaktadır (Centra, 1993). Gözlem sonrası görüşme; akran koçluğunun üçüncü aşaması olup veriler birlikte tartışılıp analiz edilmektedir. Uygulama sonrası hangi değişimlerin yapılacağına öğretmenle birlikte 
karar verilip gelecekte yapılacak çalışmalar birlikte planlanmaktadır. Bu aşamalarda eleştirel düşünceden yansıma yapma, işbirlikçi konuşma, soru sorma, geleceği planlama, koçluk sürecinde yargılayıcı dil kullanmama süreçlerin ortak noktasıdır (Brookhart ve Moss, 2015; Hanson ve Hoyos, 2015).

Portfolyo tüm eğitim öğretim kademeleri ve yetişkin eğitimlerinde kullanılabilmektedir. Terfi alacak çalışanların belgelenmesi, mesleki gelişimin izlenmesi, işgören performansının ölçülmesi, eğitim ve öğretim süreçlerine yön verilmesi, öğrenci gelişimi için bir araç oluşturma, öğretime ilişkin etkinliklerinin ve başarılarının kapsamlı bir kaydının tutulması, öğrenci öğrenmesini zenginleştirme gibi birçok faydası bulunmaktadır (Chitpin ve Simon, 2009; Lorenzo ve Ittelson, 2005). Özellikle öğretim süreçlerinde kullanılan portfolyolar, öğrenci öğrenmesini zenginleştirirken, öğretmen portfolyoları öğretime ilişkin etkinliklerin ve başarıların kapsamlı bir kaydının tutulması yönüyle etkilidir (Mues ve Sorcinelli, 2000; Wright ve Miller, 2000). Campbell vd., (1997) portfolyoyu mesleki gelişimin sistematik olarak belgelendirilmesi olarak tanımlarken, Doolittle (1994) öğretmeni eğitim öğretim süreçlerinde geliştiren belgelerin toplanması olarak ifade etmiştir. $\mathrm{Bu}$ belgeler problem çözme raporları, gözlem kayıt listeleri, ders planları, öz değerlendirmeler, belirlenen hedefler, deney sonuçları, video, ses kayıtlarl, okunan bilimsel makaleler, öğretmen ve öğrenci anekdotları, değerlendirme kağıtları, fotoğraflar, günlükler, sanatsal çalışmalar, gezi sonrası değerlendirme, öğretimle ilgili inançlar, öğretim programı, öğrenci çalışma örnekleri, mesleki yetiştirme içerikleri ve mesleki gelişim etkinlikleri olarak sıralanabilir (Aydın, 2013 ; Erbil, 2003; Kışla ve Uzun, 2005; Wolf, 2006). Akran koçluğu diğer denetim yöntemleriyle birleştirilebilir. Zepeda' ya (2016) göre akran koçluğuyla beraber portfolyo yöntemi kullanan eğitimciler, sınıf içi öğretimde yapılan uygulamalarının sonuçlarını daha somut olarak görebilmektedirler. Portfolyolar, bir tür öğrenci değerlendirme biçimi olarak kullanılmasına (Snadden, 2002) rağmen son zamanlarda yetişkinler tarafından da kullanılan bir tür denetim ve değerlendirme aracı olarak kullanılmaktadır (Lorenzo ve Ittelson, 2005; Shulman, 1988; Toptaş, 2017). 


\section{Araştırmanın Amacı}

Özetle, akran koçluğu öğretmenin meslektaşı ile çalışmasını esas alıp daha rahat düzeyde iletişim kurmasını sağlamakta ayrıca mentörlük veya diğer denetim modellerinde yer alan hiyerarşik bir konumu içermemektedir (Knight, 2011; Sullivan ve Glanz, 2000). Eşitlikçi, iletişimci, insancıl, karşılıklı güvene dayalı, öğretmen odaklı, öğretmenin kişisel ve mesleki gelişimini esas almaktadır. Portfolyo yöntemi ise öğretmenin, sınıf içi uygulamalarda karşılaştı̆̆ 1 sorunlarda araştırma yapmasına olanak verip, öğretim yöntem ve teknikleri konusunda kendini kontrol edebilmesini sağlamakta ve gerçekleştirdiği uygulamaları kayıt altına almasına yardımcı olmaktadır. Portfolyo ve akran koçluğu meslektaşlarıyla deneyim ve bilgi paylaşımı yapabilmesi, süreç bazlı bir denetim ve performans değerlendirme yöntemi olması (Chitpin ve Simon, 2009; Mues ve Sorcinelli, 2000; Shulman, 1988; Wolfson ve Willinsky, 1998) nedeniyle bu yöntemlere odaklanılarak araştırma yapılması önemli bulunmuştur. Alanda yapılan mevcut araştırmalarda öğretim denetiminde denetleyici kişinin hiyerarşik bir konuma oturtulması halinde, öğretim denetimi etkililiği ve öğretmen gelişimini olumsuz etkileyen bir durum olduğu belirtilmiştir. Bu soruna çözüm bulmak adına demokratik ve eşitlikçi olan bu yöntemlerde araştırma yapmak ayrıca önemli bulunmuştur. Alanyazın incelendiğinde öğretim denetimi temelinde akran koçluğu ve portfolyo yöntemlerinin kullanıldığı çalışmaların fazla olmadığı, portfolyo yönteminde özellikle öğrenci temelli çalışmaların çok olmasına rağmen öğretmenin aktif olarak kendisinin sürece katıldığı çalışmaların olmaması bu çalışmayı önemli kılan bir başka nedendir. Araştırılan bir hususta kapsamlı ve derinlemesine bir anlayış kazandırmak amacıyla nitel araştırma yönteminin seçilerek çalışmanın gerçekleştirilmiş olması bakımından da araştırmanın ilgili alan yazına katkı sağlayacağı öngörülmektedir. Araştırmada temel amaç öğretim denetiminde, akran koçluğu ve portfolyo yöntemleri kullanılmasının etkililiğinin öğretmen görüşleri doğrultusunda incelenmesidir. Bu doğrultuda araştırmanın problem cümlesi şu şekilde tanımlanmıştır: Öğretimin denetiminde akran koçluğu ve portfolyo yöntemlerinin kullanılmasının etkililiği nedir? Araştırma kapsamında şu alt problemlere cevap aranmıştır:

1. Öğretim denetiminde kullanılan yöntemlerden hangisinin öğretmenin gelişimine daha fazla katkı sağlayacağını düşünmektesiniz? 
a) Klinik Denetim b) Akran Koçluğu c) Portfolyo d) Mentörlük

e) Eylem Araştırması f) Gelişimsel Denetim

2. Sizce öğretim denetiminde "akran koçluğu yöntemi" kullanmanın etkililiği nedir? Nedenleriyle açıklayınız.

3. Öğretimin denetimine yardımcı bir yöntem olan "portfolyo yönteminin" etkililiği nedir? Nedenleriyle açıklayınız.

\section{Yöntem}

\section{Araştırma Modeli}

Bu çalışmada nitel araştırma yöntemi kullanılmıştır. Nitel araştırma algıları ve olayların doğal ortamları içerisinde betimleme yapmaya imkân sunan, katılımcıların bakış açısından yansıtma esasına dayalı gerçekçi ve bütüncül bir biçimde ortaya konulmasına yönelik bir süreç izler. Çalışmada nitel araştırma yöntemlerinden olan durum çalışması deseni kullanılmıştır. Durum çalışması, güncel yaşanan bir durumun kendi yaşamı bağlamında değerlendirilmesine olanak sağlamaktadır. En belirgin özellikleri ise araştırılan problemin bütüncül bir yaklaşımla ele alınabilmesi, olayın derinlemesine çalışılmasına imkân vermesi, daha çok neden, nasıl, niçin sorularına cevabın arandığı bir ya da birkaç durumu kendi sınırları içinde analiz etme fırsatı sunması olarak sıralanabilir (Creswell, 2016; Merriam, 1998; Yıldırım ve Şimşek, 2011).

\section{Çalışma Grubu}

Araştırmanın çalışma grubunu Sivas ili merkezinde görevli 2017-2018 eğitim-öğretim yılında, farklı okullarda görevli 25 ilkokul müdürü ve 25 sinıf öğretmeni oluşturmaktadır. Araştırmada amaçlı örneklem yönteminden olan ölçüt örnekleme kullanılmıştır. Ölçüt örnekleme araştırmacı tarafından belirlenen kaideler çerçevesinde bilgi kaynağının zengin olduğu, nitelikli veri sağlayan örneklemedir (Marshall ve Rosmann, 2016; Patton, 2005). Okul müdürlerinin ilkokul kademesinde görev yapması ve öğretmenlerinde sınıf öğretmenliği branşın da olmasına dikkat edilmiştir. Katılımclar çalışmaya kendi istekleri doğrultusunda katılmıştır. Katılımcların demografik bilgileri şu şekildedir: Görüş bildiren katılımcıların \%46'sı kadın, \%65'i 
erkek olup, \%88'i lisans, \%12'si yüksek lisans mezunudur. Mesleki kıdemi incelendiğinde katılımciların \%36' si (1-10) y1l, \% 46's1 (11-20) yıl, \%10' u (21-30) yıl, \%8'i (31- üstü) yıl arasındadır. Katılımciların \%50' si sınıf öğretmeni \%50'si okul müdürüdür. Katilımcların \% 28'i (20-30), \% 44'ü (3140), \%20'si (41-50), \%8'i (51-60) yaş aralığına sahiptir.

\section{Verilerin Toplanması}

Veri toplama yöntemi olarak odak grup görüşmesi seçilmiştir. Bu görüşme yönteminin seçilme nedeni aynı anda birden fazla insanla toplanma imkânı, moderatör eşliğinde yürütülmesi, veri miktarını ve çeşitliliğini arttıran bir yöntem (Robson, 2015) olmasıdır. Odak grup görüşmesinde kişilerin düşüncelerini özgürce ifade edebileceği, ortaya atılan hipotezi onaylatmaya dayanmayan rahat bir tartışma ortamı oluşturulması esastır (Creswell, 2016; Krueger, 1994). Özellikle çalışmada bu kurala dikkat edilmiştir. Çalışmada araştırmacılar tarafından ilgili literatür taranmış ve yarı yapılandırılmış görüşme soruları oluşturularak yönlendirilmiştir. Görüşme soruları eğitim yönetimi denetimi alanından iki uzman tarafından incelenerek, gerekli olan düzeltmeler yapılarak son şekli verilmiştir.

\section{Verilerin Analizi}

Araştırmada içerik analizi yöntemi kullanılmıştır. İçerik analizinde temel hedef, elde edilen verileri daha açıklanabilir hale getirmektir. Fark edilemeyen birçok kavram ve temalar bu analizle daha kolay keşfedilebilir. İçerik analizinde temelde yapılan işlem, birbirine benzeyen verileri belirli kavramlar ve temalar çerçevesinde bir araya getirmek ve bunları okuyucunun anlayabileceği bir biçimde organize ederek yorumlamaktır (Yıldırım ve Şimşek, 2011). Katılımcılara yöneltilen görüşme soruları, çalışmanın alt amaçlarını teşkil etmektedir. Bu alt problemlerin her biri ayrı tema olarak kabul edilmiştir. Katılımcı görüşlerinden doğrudan alıntılar yapılarak çalışma betimlenmiştir. Katılımcıların görüşleri aktarılırken okul müdürleri için " $\mathrm{M}$ ” öğretmenler için "Ö" kısaltması kullanılmıştır. 


\section{Geçerlik ve Güvenirlik}

Bu çalışmada verilerin geçerlik ve güvenirlik analizleri yapılmıştır. İç geçerliliğin (inandırıcılık) sağlanması için, katılımcılardan elde edilen verilerden oluşturulan sonuçlar, ilgili alan yazısındaki diğer çalışma sonuçlarıyla karşılaştırılmıştır. Toplanan verileri katılımcıların görmesi sağlanmış, veriler teyit ettirilmiş, gerektiğinde düzeltilmiştir. Dış geçerliğin (aktarılabilirlik) sağlanması için elde edilen verilerden doğrudan alıntılar yapılarak verileri doğrulayan görüşler örneklenmiş yeterli düzeyde betimleme yapılmaya çalışılmıştır. Dış güvenirliğin (teyit edilebilirlik) sağlanması için çalışmada yer alan katılımcıların demografik özellikleri açık bir şekilde tanımlanmış, veri toplama, analiz etme, tartışma ve sonuç aşamaları açı ve net bir şekilde ortaya konulmuş, elde edilmiş ham veriler gerektiğinde incelenmek üzere saklanmıştır (Creswell, 2016). İç güvenirliğin (tutarlık) sağlanmasında veri toplamak için oluşturulan soruların açık ve anlaşılır olmasına dikkat edilmiş, veriler ayrıntılı ve amaca uygun bir şekilde toplanmıştır (Merriam, 1998).

\section{Bulgular}

Bu bölümde, araştırmadan elde edilen bulgular değerlendirilmiş ve tablolaştırılarak bunlara yönelik yorumlar yapılmıştır.

Öğretmen Gelişimine Katkı Sağlayan Öğretim Denetimi Yöntemlerine İlişkin Bulgular

Tablo.1 Öğretmen Gelişimine Katkı Sağlayan Öğretim Denetimi Yöntemlerine İlişkin Bulgular

\begin{tabular}{lll}
\hline Tema & & Frekans \\
\hline Ö̆̆retmen Gelişimine & Akran Koçluğu & 31 \\
\cline { 2 - 3 } $\begin{array}{l}\text { Katkı } \\
\text { Sağlayan Ö̆̆gretim }\end{array}$ & Portfolyo & 19 \\
\cline { 2 - 3 } $\begin{array}{l}\text { Denetimi } \\
\text { Yöntemleri }\end{array}$ & Eylem Araştırması & 9 \\
\cline { 2 - 3 } & Mentörlük & 6 \\
\cline { 2 - 3 } & Gelişimsel Denetim & 3 \\
\cline { 2 - 3 } & Klinik Denetim & 3 \\
\hline
\end{tabular}

Tablo.1 incelendiğinde katılımcllar genel olarak akran koçluğu ve port folyoyu sınıf içi uygulamalar yoluyla öğretmen gelişimine katkı sağlayan 
öğretim denetimi yöntemleri olarak görmektedir. Buna ilişkin katılımcı görüşleri detaylı olarak çalışmanın ilerleyen kısımlarında sunulmuştur.

\section{Öğretimin Denetiminde Akran Koçluğu Yönteminin Etkililiğine İlişkin Bulgular}

Tablo. 2. Öğretimin Denetiminde Akran Koçluğu Yönteminin Etkililiğine İlişkin Bulgular

\begin{tabular}{|c|c|c|c|}
\hline Tema & Alt Tema & Kod & $\begin{array}{r}\text { Fre- } \\
\text { kans }\end{array}$ \\
\hline \multirow{9}{*}{ 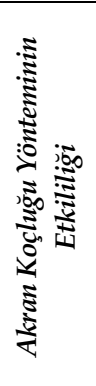 } & \multirow{6}{*}{$\begin{array}{l}\text { Olumlu } \\
\text { yönler }\end{array}$} & Deneyimli öğretmenden tecrübe aktarımının olması & 15 \\
\hline & & Öğretmen işbirliği ve iletişiminin artması & 12 \\
\hline & & $\begin{array}{l}\text { Sorunlara yönelik farkındalı̆̆ın oluşması ve çözüm yollarının } \\
\text { çoğalması }\end{array}$ & 10 \\
\hline & & Yenilik ve değişimle üretken olunması & 5 \\
\hline & & Öğretmenin özgüveninin artması & 2 \\
\hline & & Öğretimin niteliğinin artması & 2 \\
\hline & \multirow{3}{*}{$\begin{array}{l}\text { Olumsuz } \\
\text { Yönler }\end{array}$} & Rekabetle sorunların oluşması & 5 \\
\hline & & Akran çalışmalarında denetim etkililiğinin sağlanamaması & 4 \\
\hline & & İletişimin bozulması & 3 \\
\hline
\end{tabular}

Tablo.2 incelendiğinde "akran koçluğunun etkililiği "ne olumlu görüş bildiren katılımcılar genel olarak; Akran koçluğu yöntemi ile deneyimli öğretmenlerden tecrübe aktarımının olduğu, öğretmenler arasında işbirliği ve iletişimin arttığı, sorunlara yönelik farkındalığın artmasıyla çözüm yollarının çoğaldığı, öğretmenin değişimle beraber yenileneceği ve üretken olacağı şeklinde olumlu değerlendirmelerde bulunmuşlardır. Bu çerçevede katılımcıların bu yöndeki ifadeleri örneklenirse; Akran koçluğu yönteminin öğretmenler arasında tecrübe paylaşımını sağladığı, iletişimi arttırdığı, sorunların çözümüne katkı sunduğunu M7: “...Bir öğretmenin deneyimli başka bir meslektaşından öğreneceği çok şey vardır. Çünkü deneyimli öğretmen daha önceden benzer sorunlar yaşadığı için tecrübe sahibidir... Öğretmen süreçte yardım isteyecek birisini bulamadığında sorunlara çözüm üretmeleri uzun zaman alabilmektedir..." şeklinde dile getirirken, Ö7 ise, "Akran koçluğunun eğitimin kalitesini arttıracağına ve sorunlara büyük oranda çözüm olacağına inanıyorum. Çünkü farklı bilgi ve tecrübeye sahip meslektaşlarm ortak çalışması söz konusudur. Kişilerin olaylara farklı bir bakış açısı geliştirmesini sağlayarak öğretmenleri daha fazla araştırmaya sevk edeceğine inanıyorum.” şeklinde dile getirmiştir. Ö9 ise, “Ö ̆gretmenler sinıfin durumuna göre farklı uygulamalar yaparak zaman içerisinde deği- 
şik tecrübeler edinmektedir. Bu uygulama ve tecrübeler paylaşılarak sorunlara çözüm yolu bulunabilir. Bu şekilde akran öğretmen kendini geliştirir." diyerek tecrübe paylaşımının sınıf içi sorunların çözümüne katkı sunacağını belirtmiştir. Ö12, akran koçluğu yönteminin sınıf içerisinde öğretmen etkililiğini arttırabileceğini: "Akran koçluğuyla sımıf içi uygulamalarla verimliliğin kesinlikle artacağııı düşünüyorum. Zaten ders zümre öğretmenleri sınıf dışı etkileşim halinde olan tecrübe paylaşımı yapan öğretmenlerdir. Bu tecrübeleri sını içine taşımaları ve birbirlerini gözlemlemeleri, eksik olan şeylerde kafa kafaya vermeleri "Bir elin nesi var, iki elin sesi var." misali eksikliklerin giderilmesi sayesinde öğretimin daha etkili olması yolunda güzel bir uygulama olacaktır." şeklinde belirtmiştir. Akran koçluğu ile öğretmenler arasında işbirliğinin gelişeceğini ve değişimi teşvik edeceğini Ö2: “Öğretmenler arasında ki karşıllklı sayğ, güven ve iletişimi sağlayabilir. Farklı fikir ve tecrübeye sahip kişililerin ortak çalışması farklı bakış açısı kazandırarak araştırmaya ve gelişmeye seok edebilir." şeklinde açıklamıştır.

Akran koçluğunun etkililiğine olumsuz yönde görüş bildiren katılımc1lar; Meslektaşlar arasında rekabetin oluşması, akranlar arasında yapılan çalışmalarda denetim etkililiğinin sağlanamaması, iletişimin bozulması şeklinde gerekçeler ileri sürmüşlerdir. Bu çerçevede M11: “Akran koçluğu öğretmenler arasında yarışı arttırır. Birbirlerine baskınlık kurmaktan kaynaklı ağı eleştiriler ortaya çıkabilir. Bu durum da iletişim problemleri ve çatışmaya sebebiyet verilebilir.." demiştir. Ö19, öğretmenlerin eleştiriye açık olmadıklarını iletişimin bozulacağını "Zamanla rekabete dayalı sıkıntılar oluşabilir. Öğretmenler eleştiriye ve gelişime açı değiller..." M10, ise "Meslektaşlar arasındaki yakın ilişkiler nedeniyle gerçek anlamda denetim sağlanamaz. Meslektaşlarm denetim bağlaminda gerçek bir etki oluşturması mümkün değildir." şeklinde belirterek akran koçluğu yönteminin etkili bir öğretim denetim yöntemi olmadığını ifade etmiş̧ir.

\section{Öğretimin Denetiminde Portfolyo Yönteminin Etkililiğine İlişkin Bulgular}

Tablo.3 incelendiğinde katılımcıların portfolyo yönteminin etkililiği konusunda; Bilgi ve tecrübe aktarımı sağlayan; öğretmenlerin sınıf içi sorunlara yönelik farkındalığı arttıran; bireysel ve mesleki gelişimine katkı sunan; sınıf içi sorunların ve çözüm yollarını kayıt altına alan; öğretmenin bir bütün olarak değerlendirildiği uzun süreçli bir denetim yöntemi olduğu gibi görüşlerin öne çıktığı söylenebilir. 
Tablo 3. Öğretimin Denetiminde Portfolyo Yönteminin Etkililiğine İlişkin Bulgular.

\begin{tabular}{|c|c|c|c|}
\hline Tema & Alt Tema & Kod & Frekans \\
\hline \multirow{13}{*}{ 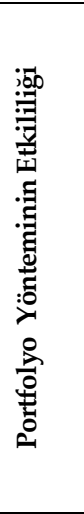 } & \multirow{7}{*}{ 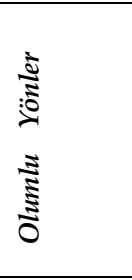 } & Bilgi ve tecrübe aktarımı sağlaması & 14 \\
\hline & & Bireysel ve mesleki gelişime katkı sunması & 13 \\
\hline & & Sorunları ve çözüm yollarını kayıt altına alması & 11 \\
\hline & & Sınıf içi sorunlarda farkındalığın artması & 10 \\
\hline & & Uzun süreçli bir denetim imkanı sağlaması & 9 \\
\hline & & İşbirlikçi çalışmanın ve iletişimin artması & 4 \\
\hline & & Öğretimin niteliğine katkı sunması & 2 \\
\hline & \multirow{3}{*}{ 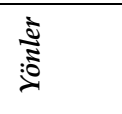 } & Gerçek anlamda uygulanamaması & 8 \\
\hline & & Öğretimdeki sorunları tespit etmemesi & 5 \\
\hline & & Öğretimi aksatması & 2 \\
\hline & \multirow{3}{*}{$\begin{array}{l}\stackrel{N}{D} \\
\stackrel{0}{\Xi} \\
0\end{array}$} & Gelişime istekli olunmaması & 2 \\
\hline & & İş yükü olarak görülmesi & 2 \\
\hline & & Öğretmen niteliğine bağlı olması & 2 \\
\hline
\end{tabular}

Bu çerçevede M11, "Portfolyo denetimi sayesinde öğretmen bir bütün olarak değerlendirilecektir. Öğretmenin kendini denetlemesi, sorunlara çözüm bulması açısından faydalı olacaktır..." diyerek yöntemle sınıf içi sorunlara çözüm bulunacağını ve özdenetim sağlayabileceğini ifade ederken; M16 ise portfolyo ile öğretmenin etkili olan çözüm yollarını seçme şansına sahip olacağını, sorunlar karşısında farkındalığının artacağını şu şekilde açıklamıştır: “Öğretmen portfolyo denetimi ile zaman içerisinde karşılaştı̆̆ı problemleri ve çözüm yollarm kayıt altına alacak, problem-çözüm eşlemesinde hangi çözümün daha etkili olduğu konusunda ön bilgisi oluşacak, bu yolla öğretmen kendisinin güçlü ve zayıf yönlerini de anlama firsatı yakalamış olacaktır..". Portfolyonun mesleki yenilenme ve gelişim sağladığını Ö21:"Çă̆ımız sürekli değişmektedir. Biz de çă̆ın getirdiği yeniliklere ayak uydurmalı, eksikliklerimizi görmeli, geliştirme yolları aramalıyız. Eğer bir sorun yaşıyorsak üstünü örtmeden çözüm yolu bulmalıyız ve mesleğimizde yenilenmeliyiz. Bunu portfolyo ile sağlayabiliriz..." sözleriyle açılık getirmiştir. Ö12 ise " Portfolyo yöntemiyle sınıf içi uygulamalar bazında kesinlikle gelişeceğimizi düşünüyorum. Maalesef öğretmen mezun olduktan sonra eğitim camiasında sistemden kaynaklı tekdüzelik ve hantallıktan dolayı sürekli olarak gerilemektedir. Öğretmenin uzun yıllar boyunca kendini geliştirme kapsamında uygulanabilecek en güzel çalışmalardan birinin de portfolyo denetimi olabileceğini düşünüyorum." sözleriyle portfolyonun mesleki gelişine ve yenilenmeye katkı sunacağına vurgu yapmıştır. Ö17 ise: "..Portfolyo süreciyle araştırma yaparak bazı şeyleri kaydetmek tecrübemize ve bilgimize katkı sunabilir. Öğretmenin iş 
yükünü arttıracağından göstermelik hazırlamanın da önüne geçilmelidir..." sözleriyle portfolyo ile öğretim sürecinde sorunların kayıt altına alabileceğinden bahsetmiştir.

Olumsuz yönde görüş bildiren katılımcılar genel olarak; Portfolyo yönteminin gerçek anlamda uygulanamayacağı; öğretimdeki sorunların tespit edemeyeceği; angarya ve iş yükü olarak algılanacağı; öğretimi aksatacağı; öğretmenin araştırma ve gelişime açık olmadığı; öğretmen niteliğine bağlı olduğu şeklinde görüş ifade etmişlerdir. Bu çerçevede M14: "Portfolyo denetimini incelediğimiz zaman çok etkileyici gözüküyor. Fakat teoride düşündüğümüz şekliyle uygulanabileceğini düşünmüyorum. Öğretmenlerimizin araştıran, okuyan, akademik çalışmalara önem veren kesiminin çok az olduğunu görmekteyiz. Küçük bir eleştirimizde bile hemen tepki verdiğini de düşünürsek birçok kişinin eksikliğini kabul edip bunu ortadan kaldırmak için araştırmalar yaptp formlar geliştirip kendi eksikliklerini gidermeye çalışacağın düşünmek açıkçası çok akılcı değildir..."diyerek öğretmenlerin kendilerini geliştirmediklerini, araştırma yapmadıklarını, eleştiriye açık olmadıklarını, formlarla yapılan çalışmaları angarya olarak gördüklerini ve öğretmen niteliğinin istenen düzeyde olmadığını ifade ederken; Ö7: “...Öğretmen verimli zamanın bu tür işlere harcamak zorunda kalır. İş yükünü arttırır. Daha verimli işlere imza atamaz. İşteki sorunları belirleyebilir fakat sorunları çözemez..." şeklinde oluşabilecek iş yükü konusuna ve sınıf içi sorunların bu yöntemle çözülemeyeceğine dikkat çekilmiştir. Benzer şekilde M 20 ise, "Yöntemin faydalı olması güçtür. Öğretmen ders dışı araştırma inceleme ve çalışmaları angarya olarak görmektedir. Öğretmende evrak işleri her zaman fazladan iş yükü getirebilir düşüncesi hâkimdir. Okul ders çalışma saatleri ve okul çalışma ortamı bu türden çalışmalara firsat vermiyor. $M E B^{\prime}$ in bu konuda çok iyi çalışması ve ön hazırlık yapması yasal alt yapıyı güçlendirmesi gerekir. Çalışan öğretmen ile çalışmayan öğretmen arasında farkllık yoktur. İdarecinin konumu ayrıca güçlendirilmeli yaptırım yetkisi olmalı ki bu tür çalışmalar iyi işleyebilsin ve idare tarafindan takip edilebilsin..."diyerek bazı endişelerini dile getirmiş olup portfolyo yönteminin etkililiği bağlamında olumsuz değerlendirmelerde bulunmuştur

\section{Tartışma Sonuç ve Öneriler}

$\mathrm{Bu}$ araştırmanın amacl; öğretim denetiminde, akran koçluğu ve portfolyo yöntemleri kullanılmasının etkililiğinin öğretmen görüşleri doğrultusunda incelenmesidir. Araştırmanın gerçekleştiği il, katılımcılardan elde edilen 
verilerle kısıtlı olmak suretiyle çalışma neticesinde elde edilen sonuçlar alanda bulunan araştırmalarla karşılaştırılmıştır. Karşılaştırma neticesinde diğer araştırma sonuçlarıyla benzerlik gösterdiği görülmektedir. “Öğretmen gelişimine katkı sağlayan öğretim denetimi yöntemleri" konusunda katılımc1 okul müdürleri ve öğretmenler özellikle akran koçluğu ve portfolyo yöntemlerini, öğretmene katkı sunan öğretim denetimi yöntemi olarak ön plana çıkartmışlardır. Çalışma sonuçlarını destekleyen araştırmaların bazıları şu şekilde verilebilir: Deborah, Edward, Mercey (2017) öğretim denetimi uygulamalarıyla müfredat kapsamı, öğretim süreçlerinin iyileştirilmesi konularında öğretmenlere mesleki yarar sağladığını araştırmasında belirtmiştir. Oja (2002) işbirlikçi denetim sürecine (Akran koçluğu vb.) katılan katılımcıların hem okul uygulamaların hem de teorik bilgileri geliştirdiğini, işbirlikçi çalışma isteğinde olduğu ve bu tür öğretim denetimi ortaklığında çalışanların mesleki gelişim sağladığını göstermiştir. Chalong , Tawisook, ve Ratanaolarn, (2018) Tayland'daki özel bir ilköğretim okulunda mesleki gelişimi kolaylaştırmak ve ilkokul matematik ve fen bilgisi öğretmenlerinin öğretim yeterliklerini artırmak için bir koçluk sistemi geliştirmiş ve uygulamıştır. Koçlar, öğretmenler ve öğrencilerle yapılan görüşmeler ve anketler, sonucunda akran koçluğu çalışmalarından öğretmenlerin yüksek derecede memnun oldukları, bu sistemin yeni alternatif yöntemleri keşfetmelerini sağladığını ve becerilerini ve etkinliklerini desteklediğini ifade etmiştir. Bowers (2017), öğretmen adaylarına akran koçluğu eğitimi vermiş, sınıf içi uygulamalar yaptırmıştır. Araştırma sonucunda akran koçlarının öğrenci ve öğretim çıktılarına yönelik yansımalarına vurgu yaparak, öğretmen gelişimine olumlu katkısını açığa çıkarmıştır. Özmen (2018) öğretmenlerle yaptığ1 araştırmada, koçluk becerileri göstermenin öğretmen açısından önemli olduğunu ortaya koymuştur. Benzer bir sonuç ise Darling (2001)'in yaptı̆̆1 çalışmada görülmektedir. Darling (2001) öğretmen adaylarının mesleki gelişiminde portfolyo kullanımının faydalı ve etkili bir yöntem olduğunu belirtmiştir. Tüm bu sonuçlar "Öğretmen gelişimine katkı sağlayan öğretim denetimi yöntemleri" bağlamında ortaya konan sonuçlarla tutarlılık arz etmektedir.

"Akran koçluğu yönteminin etkililiğine" ilişkin olarak; Akran koçluğu yöntemi ile deneyimli öğretmenlerden tecrübe aktarımının olacağı, öğretmenler arasında işbirliği ve iletişimin artacağı, sorunlara yönelik farkındalığın artmasıyla çözüm yollarının çoğalacağı, öğretmenin değişimle beraber yenile- 
neceği ve üretken olabileceği şeklinde katılımcı görüşleri ön plana çıkıştır. Alan yazında ortaya konulan çeşitli araştırmalarda benzer sonuçlar dile getirilmiştir.Tarakcı (2019), koçluk seans sayısının bireysel performansı ve kişilerin öz yeterliliğini pozitif yönde etkilediğini analizlerde ortaya koymuştur. Benzer şekilde Truesdale (2003), öğretmen yetiştirme sürecinde akran koçluğu yöntemini kullanmıştır. Akran koçluğu eğitimi alan öğretmenlerin, eğitim almayan öğretmenlere göre sınıf içi teorik bilgileri uygulamalara daha iyi taşıdıklarını göstermiştir. Akran koçluğunun hizmetçi eğitimlerde bilginin uygulamaya dönüştürülmesinde önemli bir faktör olduğunun ortaya konulması çalışma sonuçlarıyla örtüşmektedir. Akran koçluğu yöntemiyle işbirliği ve iletişiminin sağlanmasının yanı sıra sorunlara yönelik farkındalıkta artma görüldüğü, bireysel ve mesleki gelişim sağlandığ ifade edilmişti. Bu sonuçla Prince, Snowden ve Matthews (2010)' in yaptıkları çalışma karşılaştırıldığında, paralel sonuçlara ulaşıldığı ifade edilebilir. İngiltere'de eğitim kursunda lisansüstü bir sertifikaya kayıtlı otuz sekiz öğretmenle hizmet öncesi eğitim araştırması yapılmış ve öğrenciler üniversite ders oturumlarında, okul sitesi yoluyla akran koçları ile çalışma yapmıştır. Çalışma neticesinde akran koçluğu yöntemi ile güçlü insani ilişkilerin oluştuğu, öğrenci öğretmen iletişiminin arttı̆̆ ve öğretim uygulamaları üzerinde olumlu bir etkisi olduğu, akran koçluğunun mesleki gelişim sağladığı, öğrencilerin uygulamalarını geliştirmek için yeni stratejiler sunduğu gösterilmiştir. Ayrıca Özmen (2018) tarafından yapılan çalışmada koçluk ölçeği kullanılmış, koçluk eğitimine katılan öğretmenlerin sınıf içi çalışmalarda farkındalık yaratma boyutunun uygulama düzeyinde anlamlı bir farklılık göstermesi çalışmamız sonucunda ortaya çıan "koçluğun öğretim uygulamaları üzerinde olumlu bir etkisi olduğu" sonucuyla örtüştüğü söylenebilir. Araştırmada katılımclar akran koçluğu ile denetimin daha etkili ve verimli hale geleceğini belirtmişlerdir. Lee ve Choi (2013), on kişiden oluşan beden eğitimi öğretmenleri ile dört haftalık hizmet öncesi eğitim ve on iki haftalık mikro öğrenme uygulamaları yaptırmıştır. Araştırmayla akran koçluğunun adaylarda bilgiyi yansıtmayı kolaylaştırdığı, engelleri kolay şekilde aşmasını sağladığı, olumlu yönde dönütler verilerek iyi ve etkili bir denetim modeli olduğunun belirtilmesi, çalışmada yer alan " akran koçluğu denetiminin etkililiği " sonuçlarıyla çakışmaktadır. Kısaca Bowers (2017), Lee ve Choi's (2013), Prince vd., (2010), Truesdale (2003), Tarakçı (2019), Özmen (2018)'nin elde ettikleri çalışma sonuçlarının, öğretmenler 
arasındaki bilgi ve tecrübenin taşınması, sorun ve engellerin çözümüne katkı sunması, güçlü ilişki ve iletişimin artması, bireysel ve mesleki gelişimin sağlanması ve denetimim etkililiği yönüyle ulaştığımız araştırma sonuçlarıyla örtüştüğü söylenebilir. Bazı çalışmalarda akran koçluğu uygulamalarında ortaya çıabilecek olumsuz durumların; akran koçu eşleştirmelerinden kaynaklı iletişim sorunu, akrana destek sağlama yerine rakip olma, eleştiri düzeyinin ayarlanamamasından kaynaklı denetimde objektifliğin kaybedilmesi, koçluk uygulamalarının istenilen nitelikte yapılmaması, branş farklılıkları, işbirlikçi çalışmayı sevmeme, zaman baskısı, iş yükü ve stres oluşturması olarak sıralanmıştır (Bruce ve Ross, 2008; Frazier, 2011; Grant, Green ve Rynsaardt, 2010; Gottschalk, 2014; Tarakç1, 2019). Uygulamalarda görülen bu durumun, araştırmada ortaya konulan " rekabetle sorunların oluşması, akran çalışmalarında denetim etkililiğinin sağlanamamasl, iletişimin bozulması" verileriyle tutarlılık gösterdiği ifade edilebilir.

"Portfolyo yönteminin etkililiğine" ilişkin olarak; Öğretmenlerin sınıf içi sorunlara yönelik farkındalığı artarak çözüm yollarının çoğalacağı, güçlü ve zayıf yönlerini görerek mesleki gelişimine katkı sunabileceği, sınıf içi sorunların ve çözüm yollarının kayıt altına alınabileceği, öğretmenin bir bütün olarak değerlendirilebileceği uzun süreçli bir denetim yöntemi olduğu sonuçlarına ulaşılmıştır. Alan yazında ortaya konulan çeşitli araştırmalarla benzer sonuçlar birçok kez dile getirilmiştir. Bu araştırmalardan bazıları sıralanırsa: Orbaç (2018) portfolyo uygulamaları yaptı̆̆ı çalışmasında, portfolyonun kişiye doğru sunum imkânı sağlayan, becerileri ve deneyimleri yansıtan iyi bir yöntem olduğunu çalışmasında ortaya koymuştur. Rolheiser ve Schwartz (2001), katılımcı olarak öğretmen adayların seçtiği ve portfolyo değerlendirmelerinin yapıldığı araştırmada, mesleki yaklaşım ve planlamada iyileşmelerin görüldüğü, sorunların etkili şekilde çözüldüğü, öğretmen adaylarının öğrencilere yönelik mesleki eksikliklerini gördüklerini, öğretmenlerin görev ve sorumluluk bilincinin arttığı sonuçlarına ulaşması araştırmada yer alan "portfolyo yöntemi ile öğretmenlerin sınıf içi sorunlara yönelik farkındalığı artırarak çözüm yollarının çoğalacağı" ve "öğretmenin güçlü ve zayıf yönlerini görerek mesleki gelişimine katkı sunabileceği" sonuçlarıyla benzerlik taşıdığı söylenebilir. Driessen ve Vermunt (2005), gerçekleştirdiği araştırmada, öğretmen portfolyo dosyaları, mentörler tarafından denetim ve değerlendirme aracı olarak kullanılmıştır. Portfolyonun değerlendirme süreçlerinde kullanımının öğretmen gelişimine katkı 
sunduğu bu çerçevede etkili bir denetim yöntemi olduğu ortaya konulmuştur. Jeevaratnam (2013) portfolyonun öğretmenin sınıf içi sorunlarına yönelik çözüm bulmasına katkı sunan, mesleki gelişimi sağlayan uzun süreçli değerlendirme ve denetim aracı olduğunu araştırma sonucunda belirtmiş, çalışma neticesinde ulaştı̆̆ımız "portfolyonun öğretmenin bir bütün olarak değerlendirileceği uzun süreçli bir denetim aracı olduğu" görüşünü destekler mahiyettedir. Demirkan (2019), öğretmen portfolyosu sayesinde, öğretmenin kendi öğrenmelerini değerlendirme ve sürdürülebilir mesleki gelişimin önemine dair farkındalık kazanma fırsatı yarattı̆ını, yaşadıkları sorunların hızla çözümüne katkı sunduğunu, tecrübe paylaşımı sağlandığını, güçlü ve zayıf yönlerini gördügünü, paylaşımc bir anlayışın geliştiğini belirtmiştir. Demirkan'ın (2019) ulaştığı sonuç çalışmamızda öne çıkan "portfolyo yöntemiyle sınıf içi sorunların ve çözüm yollarının kayıt altına alınabileceği" ve "öğretmenin güçlü ve zayıf yönlerini görerek mesleki gelişimine katkı sunabileceği" sonucuyla örtüştüğü ifade edilebilir. Zepeda (2016), portfolyo denetiminin denetmen ya da meslektaş tarafından yapılacağı gibi öz yönelimli olarak da yapılabileceğini, farklı denetim modelleriyle birleştirilmesiyle mesleki öğrenmeyi destekleyeceğini ifade etmesi, yapılan çalışmanın amacına ve ulaşılan verilerin olumlu yöndeki niteliğine uygun düşmektedir. Toptaş (2017), öğretmen dosya değerlendirmesinin (portfolyo) bir denetim yaklaşımı olarak kullanım alanlarını, amacını, faydaları ve sınırlılıklarını tartıştığı çalışmada ağırlıklı olarak hizmet öncesi aday öğretmenleri değerlendirmek için kullanıldığını, yurt dışında yükseköğretimde öğretmen adaylarının değerlendirilmesinde kullanılmasına rağmen Türkiye'de ise bu kullanım biçiminin yaygın olmadığını, hizmet öncesi aday öğretmenlerde kullanımının etkililiği konusunda da araştırmaların yetersiz olduğunu ifade etmiştir. Ayrıca alanda yapılan çalışmalarda portfolyonun evrak yükü oluşturduğu, zaman kaybına neden olduğu, ekstra çalışma yüküyle stres oluşturduğu, değerlendirme sürecinde nesnellik ve etkililikte yetersizlik gibi bazı olumsuz değerlendirmelerin yapıldığı görülmüştür (Demirkan, 2019; Ersoy, 2006; Orbaç, 2018; Toptaş, 2017). Bu değerlendirmelerin araştırmada ortaya konulan "portfolyonun; gerçek anlamda uygulanamaması ve kağıt üstünde kalması, zaman ayrılması gerektiğinden öğretimi aksatması, angarya ve iş yükü olarak görülmesi" sonuçlarıyla tutarlılık gösterdiği görülmektedir. Çalışma neticesinde katılımcı okul müdürü ve öğretmenler; Genel anlamda öğretim denetiminde akran koçluğu ve port- 
folyo yöntemlerinin kullanılmasının etkili yöntemler olduğunu düşünmektedirler. Ayrıca bu yöntemlerin öğretmenin sınıf içi uygulamalarda karşılaştığı sorunların çözümüne katkı sunan, mesleki gelişim sağlayan öğretim denetimi araçları olduğunu belirtmişlerdir.

Ortaya çıkan sonuçlar bağlamında şu öneriler getirilebilir: Öğretmenler, öğretim denetiminde akran koçluğu ve porfolyo yöntemlerini kullanarak sınıf içi uygulamalardaki karşılaştığı sorunların çözümüne katkı sunabilir ve bu yöntemleri mesleki gelişim veya denetim aracı olarak kullanabilirler. Öğretim denetiminde akran koçluğu ve portfolyo gibi daha demokratik yöntemlerin kullanılması konusunda pilot çalışmalar yapılarak araştırmacı ve uygulamacilara 1şık tutulabilir. 


\title{
EXTENDED ABSTRACT
}

\section{Peer Coaching And Portfolio Usage: Two Methods In Effective Instructional Supervision}

\author{
Yasin Avan - Sevilay Şahin \\ Ministry of National Education, Gaziantep University
}

Assessment of supervision outputs in educational institutions is substantial in terms of ensuring the improvement of the institution and seeing its future. Today, the development of new management approaches and the prominence of organizational learning have caused a change on the stand points of supervision (Senge, 2006; Sullivan and Glanz, 2009). New situations have emerged, such as abandoning the bureaucratic standpoint that is strict normative, orientation to humanist perceptive, motivating the teacher, vocational development of the teacher, and grounding on individual differences. Peer coaching provides the teacher to communicate with his colleague on a more comfortable level by grounding on cooperation with them. Also, it does not include a hierarchical position in mentoring or other supervision models (Knight, 2011; Sullivan \& Glanz, 2000). It is based on the personal and professional development of the teacher in respect to egalitarian, communicational approach, mutual trust, and teacher-oriented. Portfolio method, on the other hand, allows the teachers to make researches about the problems encountered in classroom practices and control themselves about teaching methods and techniques, and helps to record his practices. In the current researches in the field, it is stated that if the supervisor is placed in a hierarchical position in the teaching supervision, it is a situation that negatively affects the teaching supervision effectiveness and teacher development. It is also important to research these methods that are democratic and egalitarian in order to find a solution to this problem. When the literature is examined, the studies using peer coaching and portfolio methods on the basis of teaching supervision are not much. In the portfolio method, the absence of the studies in which the teacher actively participates in the process, although there are many student-based studies, is another reason that makes this study important. It is foreseen that the research will contribute to 
the literature in terms of the study by selecting the qualitative research method in order to gain a comprehensive and in-depth standpoint of a researched subject. The main purpose of the research is to examine the effectiveness of peer coaching and portfolio methods in teaching supervision in line with the opinions of the teachers. Accordingly, the problem statement of the research is defined as follows: "What is the effectiveness of using peer coaching and portfolio methods in the teaching supervision?" Qualitative research method was used in the study. It follows a process for the realization of the qualitative research perceptions and events in a natural and holistic way, based on reflection with the perspective of the participants, which allows to describe in their natural environment. Case study pattern, which is one of the qualitative research methods, was used in the study. The study group of the research consists of 25 primary school principals and 25 classroom teachers who work in different schools in 2017-2018 academic year in Sivas city center. Criteria sampling, which is one of the purposeful sampling methods, was used in the research. Focus group discussion was chosen as the data collection method. The reason for choosing this discussion method, since it meets with more than one person at the same time, is carried out with a moderator, and increases the amount and diversity of data (Robson, 2015). In the focus group discussion, it is essential to create a comfortable discussion environment where people can express their thoughts freely, not based on affirming the hypothesis put forward (Creswell, 2016; Krueger, 1994). In particular, this rule was made point of the study. In the study, the related literature was scanned by the researchers and guided by creating semistructured discussion questions. The discussion questions were examined by two experts from the field of education management supervision, and the necessary corrections were made and finalized. Content analysis method was used in the research. The main objective in content analysis is to make the obtained data more explicable. Many unnoticeable concepts and themes can be discovered more easily with this analysis. The discussion questions addressed to the participants constitute the sub-objectives of the study. Each of these sub-problems is accepted as a separate theme. The study is described by quoting directly the participants' views. The province where the research took place was limited with the data obtained from the participants, and the results which was obtained as a result of the study were compared with the researches in the field. As a result of comparison, it 
is seen that it is similar to results of other research. The participant school principals and teachers have brought forward peer coaching and portfolio methods as the teaching supervision method, which contributes to the teachers, about the subject " Teaching supervision methods that contribute to development of the teacher". Regarding "The effectiveness of the peer coaching method", the views of participant such as there will occur experience transfer from experienced teachers with peer coaching method, cooperation and communication among teachers will increase, the solutions will increase with increasing awareness of the problems, the teacher will be renewed and productive with the change, became prominent. Regarding the "effectiveness of the portfolio method"; It has been concluded that teachers' awareness of in-class problems will increase and solutions will increase, they are able to contribute to their professional development by seeing their strengths and weaknesses, In-class problems and solutions are able to be recorded, and it is a longterm method of supervision where the teacher could be evaluated as a whole. In addition, it has been observed in the studies conducted in the field that the portfolio creates a burden of paperwork, causes time loss, creates stress with extra workload, and some negative evaluations such as inadequate objectivity and effectiveness in the evaluation process. As a result of the study, the participant school principals and teachers, in general terms, think that using peer coaching and portfolio methods in teaching supervision are effective methods. They also stated that these methods are instructional supervision tools that contribute to the solution of the problems faced by the teacher in classroom practices and provide professional development. In the context of the results, the following suggestions could be made: Teachers are able to contribute to the solution of problems faced in classroom practices by using peer coaching and portfolio methods in teaching supervision and use these methods as professional development or supervision tools. Researchers and practitioners are able to be shed light about the use of more democratic methods such as peer coaching and portfolio in teaching supervision by making pilot surveys.

\section{Kaynakça / References}

Anderson, D. (2013). Untying the knots. In the chisymposium coaching in the moment. 
Aydın, İ. (2013). Öğretim denetimi: durum saptama, değerlendirme ve geliştirme. Ankara: Pegem Akademi Yayıncilı.

Aydın, M. (2011). Çă̆daş eğitim denetimi. Ankara: Hatipoğlu Yayınları.

Bowers, D. L. (1999). Teachers' use of peer observation and feedback as a means of professional development. Southern California Universty. Doctoral Thesis . California.

Bowers, K. J. (2017). The impact of peer coaching on peer relationships and the distribution of knowledge in pre- service teachers. University of Northern Iowa. Electronic theses and dissertations. Iowa.

Browne, L. (2006). Proposing a proximal principle between peer coaching and staff development. International Journal of Evidence Based Coaching and Mentoring, 4, 31-44.

Brookhart, S. M. ve Moss, C. M. (2015). How to give professional feedback. Educational Leadership, 72, 24-30.

Bruce, C.D. ve Ross, j A. ( 2008).A model for increasing reform implementation and teacher efficacy:teacher peer coaching in grades 3 and 6 mathematics. Canadian Journal Of Educatıon, 31(2), 346-370

Bursalığlu, Z. (2000). Okul yönetiminde yeni yapı ve davranış. Ankara: Pegem Yayınları.

Campbell, D.M ., Cignetti ,P.B., Melenyzer, B.J., Nettles, D.H. ve Wyman, R.M. (1997). How to develop a professional portfolio: A manual for teachers. MA: Needham Heights.

Centra, J. A. (1993). Reflective faculty evaluation. San Francisco: Jossey-Bass.

Chalong, G., Tawisook, M., ve Ratanaolarn, T. (2018). Development of Mathematics and Science Teacher Competencies through Coaching. Creative Education, 8, 2049-2063

Chitpin, S. ve Simon, M. (2009). Even if no-one looked at it, it was important for my own development: Pre-service teacher perceptions of professional portfolios. Australian Journal of Education, 53(3), 277-293.

Creswell, J. W. (2016). Nitel araştırma yöntemleri (Çev. Ed. Bütün. M). Ankara: Siyasal Kitabevi.

Darling, L. F. (2001). Portfolio as practice: The narratives of emerging teachers. Teaching and Teacher Education, 17(1), 107-121. 
Deborah, K., Edward, K. ve Mercey, M.M.(2017). Secondary School Principals' Work Load And Instructional Supervision Practices İn Kenya: A Case Of Lower Yatta Sub-County, International Journal of Humanities Social Sciences and Education (IJHSSE), 4(2), 68-80 http://dx.doi.org/10.20431/23490381.0402007 adresinden 02/11/2019 tarihinde erişildi.

Demirkan, S. (2019).Eğitim yönetiminde alternatif denetim yaklaşımı, öğretmen portfolyosu değerlendirme: Bir literatür taraması. Karamanoğlu Mehmetbey Uluslararası Ĕ̆itim Araştırmaları Dergisi 1(1), 49-62

Driessen, E. ve Vermunt, J. (2005). The use of qualitative research criteria for portfolio ssessment as an alternative to reliability evaluation:a case study. Medical Education, 39, 214-220.

Doolittle, P. (1994). Teacher portfolio assesment. Cleraringhouse on asessment and evulation. Washington Dc .

Erbil, O. (2003). Öğrenci merkezli eğitim uygulama modeli. Ankara: Milli Eğitim Basimevi

Ersoy, A.F.(2006).Öğretmen adaylarının gelişim dosyasına dayalı değerlendirmeye ilişkin görüşleri. İlköğretim online, 5(1),85-95.

Grant, A. M., Green, L. S., and Rynsaardt, J. (2010). Developmental coaching for high school teachers: Executive coaching goes to school. Consulting Psychology Journal: Practice and Research, 62(3), 151-168. https://psycnet.apa.org/record/2010-19800-001 adresinden 03/11/2019 tarihinde alınd.

Gottschalk, M.G. (2014). How do business leaders learn in peer-group coaching? Oxford University. Doktora Tezi. İngiltere.

Guskey, T. (2014). Planning professional learning. Educational, school, and counseling psychology faculty publications. 15. 12.05.2019 tarihinde https://uknowledge.uky.edu/edp facpub/ adresinden erişildi.

Hanson, H. and Hoyos, C. (2015). The shift from-me- to-we: Schools with a coaching culture build individual and collective capacity. The Journal of Staff Development, 36(2), 42-45.

Henson, K. T. (2010).Supervision: A collaborative approach to instructional improvement. Waveland: Pr. Inc.

İlgan, A. (2012). Öğretmenlerin mesleki gelişimi ve denetimi. Ankara: Anı Yayıncilık.

Jeevaratnam, G. (2013). Portfolio as an assessment tool in the french foreign language classroom. International Journal of Scientific Research, 2(11), 155156. 
Joyce, B. and Showers, B. (1982). The coaching of teaching. Educational Leadership, 40(1), 4-10.

Kışla,S.V. ve Uzun E.(2005).Okul öncesi dönemde portfolyo değerlendirmesi. Çocuk-veli-öğretmen görüşmeleri, Eğitimde iyi örnekler konferansı. Sabanc Üniversitesi. İstanbul.

Knight, J. (2011). What good coaches do. Educational Leadership, 69(2), 18-22.

Krueger, R.A. (1994). Focus Groups: A Practical Guide For Applied Research. London: Sage.

Lee, O.and Choi, E. (2013). Utilizing peer coaching to facilitate pre-service physical education teachers reflection. The Asia Pacific Education Researcher, 22(2),147-154.

Lunenburg, F. C. ve Ornstein, A. C. (2013). Eğitim yönetimi (Çev Edit. Arastaman, G). Ankara: Nobel Yayınclik.

Lorenzo, G. and Ittelson, J. (2005). An overview of e-portfolios. Educase learning initiative. https://library.educause.edu//media/files/library/2005/1/eli3001pdf. adresinden 24/08/2019 tarihinde erişildi.

Marzano, R. J., Frontier, T. ve Livingston, D. (2011). Effective supervision supporting the art and science of teaching. Virginia: Ascd Member Book.

Marshall, C. and Rossman, G. (2016). Designing qualitative research. Sage, Thousand Oaks.

Merriam, S.B. (1998). Case study research in education, a qualitative approach. Jossey Bass Publications,

Mues, F. ve Sorcinelli, M. D. (2000). Preparing a teaching portfolio. https://cndls.georgetown.edu/media/documents/teachingportfolio Adresinden 12.10.2019 tarihinde erişildi.

Oja, S.N.(2002). Shared accountability in creating and managing collaborative supervision partnerships university of new hampshire paper presented in the symposium titled:sharing accountability in school-university partnership with a common goal of preparing, Inducting, and Retaining the Best Teachers ACTE February 25, 2002.

Orbaç, (2018).Moda tasarmmcları için portfolyo hazırlama ve örnek uygulama. Yüksek Lisans Tezi. Gazi üniversitesi, Ankara

Özmen, Ö. (2018). Lise öğretmenlerinin koçluk davramışların benimseme ve uygulama durumlarma ilişkin görüşleri. Yüksek Lisans Tezi, Ankara Üniversitesi, Ankara

Patton, M. Q. (2005). Qualitative research. New York: John Wiley \& Sons, Ltd. 
Prince, T.,Snowden, E. ve Matthews, B. (2010). Utilizing peer coaching as a tool to improve student-teacher confidence and support the development of classroom practice. Literacy Information And Computer Education Journal, $1,49-51$

Rhodes, C. ve Beneicke, S. (2002). Coaching, mentoring and peer networking: Challenges for the management of teacher professional development in schools. Journal of Service Education, 28(2), 297-309

Rice, G. (2012). Formative dialogues in teaching nonthreatening peer coaching. The Journal of Chiropractic Education, 26(1), 62.

Robbins, P. (1991). How to plan and implement a peer coaching program. Association for Supervision and Curriculum Development, 2714-2798.

Robson, C. (2015). Bilimsel araştırma yöntemleri. Gerçek dünya araştırması. (Çev. Edit Ş. Çınkır, N. Demirkasımoğlu ). Anı Yayınclık.

Rolheiser, C. ve Schwartz, S. (2001). Pre-service portfolios: A base for professional growth. Canadian Journal of Education, 26(3), 283-30

Senge, P. M. (2006). The fifth discipline: the art and practice of the learning organization. New York: Century Business.

Shulman, L.S. (1988). A union of insufficiencies: Strategies for teacher assessment in a period of educational reform. Educantional Leadership, 46(3), 36-41 http:www.ascd.org adresinden 06/04/2019 tarihinde erişildi.

Snadden, D. (2002).Portfolios attempting to measure the unmeasurable? Medical Education, 33,478

Sullivan, S. ve Glanz, J.(2000). Alternative approaches to supervision: Cases from the field. Journal of Curriculum and Supervision, 15(3), 212-235

Sullivan, S. ve Glanz, J. (2009). Supervision that Improves Teaching and Learning. California: Corwin.

Tarakçı, U. A.(2019).Örgütlerde öz yeterlilik algısı ve performans ilişkisinde kişilik profillerinin düzenleyici rolü ve koçluk hizmeti alan çalışanlar üzerine bir araştırma. Doktora Tezi. Balıkesir Üniversitesi. Balıkesir

Truesdale, W. T.(2003). The implementation of peer coaching on the transferability of staff development classroom practice in two selected Chicago public elementary schools. Doktora tezi. Loyola Universitesi, Chicago.

Toptaş, B. (2017).A contemporary approach to performance evaluation: Teacher portfolios. Journal of Human Sciences, 14(4), 4155-4170.

Wiles, J. ve Bondi,J. (2000).Supervision a guide to practice. New Jersey: Prentice Hall. 
Wolf, K. (2006). Portfolios in teacher evaluation Stronge, J. H. (Ed.) Evaluating teaching: A guide to current thinking and best practice içinde (s. 168-184). California: Corwin Press.

Wolfson, L. ve Willinsky, J. (1998). What service learning can learn from situated learning. Michigan Journal of Community Service Learning, 5, 22-31.

Wright, W. A. ve Miller, J. E. (2000). The educational developer's portfolio. The International Journal for Academic Development, 5(1), 1-5.

Xun, G. ve Land, S. (2004). A conceptual framework for scaffolding ill-structured problem-solving processes using question prompts and peer interactions. Educational Technology Research and Development, 52(2), 5-22.

Yıldırım, A. ve Şimşek, H. (2011). Sosyal bilimlerde nitel araştırma yöntemleri. Ankara: Seçkin Yayıncilık.

Zepeda, S.J. (2016). Insructional supervision: Applying tool s and concepts. (Çev. Edit. Apaydın Ç, Balcı, A). Ankara: Pegem Yayıncılık.

\section{Kaynakça Bilgisi / Citation Information}

Avan, Y. ve Şahin, S. (2020). Öğretim denetiminde akran koçluğu ve portfolyo kullanımının etkililiğinin incelenmesi. OPUSUluslararası Toplum Araştırmaları Dergisi, 16(28), 1028-1053. DOI: 10.26466/opus.676497 